\title{
Ontogeny of Orientation during the Early Life History of the Pelagic Teleost Mahi-Mahi, Coryphaena hippurus Linnaeus, 1758
}

\author{
Robin Faillettaz ${ }^{1,2, *(\mathbb{D}}$, Eve Johnson ${ }^{1}$, Patrick Dahlmann ${ }^{1}$, Alexandra Syunkova ${ }^{1}$, \\ John Stieglitz ${ }^{3}$, Daniel Benetti ${ }^{3}$, Martin Grosell ${ }^{1}\left[\right.$ and Claire B. Paris ${ }^{1, *} \mathbb{C}$ \\ 1 Department of Marine Biology and Ecology, University of Miami, Rosenstiel School of Marine and \\ Atmospheric Science, 4600 Rickenbacker Causeway, Miami, FL 33149, USA; exj201@rsmas.miami.edu (E.J.); \\ pmd73@miami.edu (P.D.); axs2375@rsmas.miami.edu (A.S.); mgrosell@rsmas.miami.edu (M.G.) \\ 2 Ifremer, STH, Station de Lorient, 8 rue François Toullec, F-56100 Lorient, France \\ 3 Department of Marine Ecosystems and Society, University of Miami, Rosenstiel School of Marine and \\ Atmospheric Science, 4600 Rickenbacker Causeway, Miami, FL 33149, USA; \\ jstieglitz@rsmas.miami.edu (J.S.); dbenetti@rsmas.miami.edu (D.B.) \\ * Correspondence: robin.faillettaz@ifremer.fr (R.F.); cparis@rsmas.miami.edu (C.B.P.)
}

Received: 6 July 2020; Accepted: 29 September 2020; Published: 8 October 2020

\begin{abstract}
Understanding the orientation behavior and capabilities in early life history (ELH) of fishes is critical for studying their dispersal but has, surprisingly, never been tested in any pelagic species. We here investigate the ontogeny of orientation and swimming abilities of the pelagic Coryphaena hippurus Linnaeus, 1758 larvae, hereafter mahi-mahi, through their ELH stages using the Drifting In Situ Chamber (DISC) in a laboratory setup. The DISC was deployed in a large $\left(3 \mathrm{~m}^{3}\right)$ circular aquarium in order to control the stimulus perceived by the fish and to identify behavioral response at the individual, developmental stage, and population levels. A total of 79 individual ranging from 7 to 23 days post hatch and from preflexion to early juvenile stages were exposed to a directional light mimicking the sun's position. Orientation towards the light direction was tested by switching the light by $180^{\circ}$ among trials. To compare the orientation among development stages, we scaled the directionality by the swimming ability, therein defined as "directionality competence". The results show that while mahi-mahi directionality competence increases through ontogeny, they acquire a positive and directional phototaxis behavior at the flexion stage. This potential solar orientation is kept through the early juvenile stage. Mahi-mahi may thus be able to use the sun as a compass in the open ocean as observed in the larval stages of demersal species seeking for settlement habitats. This ability notably develops before the improvement of their swimming capabilities, suggesting that early orientation—even at micro-scale—and swimming capabilities may be equally important for the survival of the ELH stages of pelagic species.
\end{abstract}

Keywords: early life history stages; Coryphaena hippurus; common dolphinfish; mahi-mahi; behavior; orientation; phototaxism; ontogeny; directionality competence

\section{Introduction}

Phototactic behavior, i.e., the attraction or repulsion in response to a light stimuli, is among the most widespread behaviors in the animal kingdom; it is found from bacteria [1] to teleost fishes [2], among others. While the ecological drivers of phototaxis remain unclear, phototaxis in fishes has mostly been studied from an aquaculture perspective for which several applications have emerged, such as to cope with the sinking syndrome of early life history (ELH) stages at night [3,4]. From an ecological perspective, describing the sensitivity and preference to light intensity provides information on the 
visual acuities and enables inference on the vertical distribution of larval stages [5], and, if sampled at a high frequency, it may even reveal their orientation abilities [6].

Noteworthily, the last two decades revealed that the late larval stages of demersal fish possess strong orientation abilities [7-11]. While most larvae swim directionally in the ocean, their orientation accuracy seems unrelated to their growth (reviewed in [12]). In Caranx ignobilis, orientation developed before the postflexion stage ( $\leq 8 \mathrm{~mm} \mathrm{SL}$ ) and did not improve with size and age as swimming did [13]. Three sparids species showed a marked ontogeny of orientation, with individuals smaller than $8 \mathrm{~mm}$ swimming randomly while bigger individuals were directional, yet all were already postflexion stages [14]. Understanding these ontogenic changes is critical since, in theory, early orientation during ontogeny is imperative to modulate dispersal distances [15-19] and incorporating ontogenic-dependent behavior was proven necessary to match the observed dispersal kernels of Plectropomus maculatus (Bloch, 1790) ELH stages [20]. However, as critical as ontogenic changes in behavior are for modeling purposes [18,21], they still remain largely overlooked in biophysical models $[16,22]$. Thus, while most fish larvae possess the ability to swim directionally from the postflexion stage, still little is known about the orientation behavior and on its ecological relevance throughout ontogeny and in earlier stages in particular.

There have been numerous studies done on the phototactic behavior of larval fishes (e.g., Atlantic herring Clupea harengus Linnaeus, 1758, turbot Scophthalmus maximus Linnaeus, 1758, Atlantic cod Gadus morhua Linnaeus, 1758, Japanese flounder Paralichthys olivaceus (Temminck and Schlegel, 1846) [5,23-25], but few tested light as a cue for circular orientation and only in a freshwater species, the zebrafish Danio rerio (Hamilton, 1822) [6,26]. In its natural habitat, this species is systematically exposed to multiple visual and sonic directional cues, some of which are also used by the settlement stage of demersal fish species in the coastal areas (e.g., visual: substrate [27], sound: breaking waves, and benthic species [28]). In earlier stages of coral reef fishes and for pelagic species navigating through the open ocean like mahi-mahi, the diversity of directional cues available for the ELH stages may thus be largely reduced. For instance, tidal flows and estuary plumes create chemical halos that may be entrained alongshore and offshore by coastal currents $[29,30]$. However, even though reef fish larvae respond to ebb plumes in the open ocean by changing their swimming behavior, this perceived chemical cue is not directional for millimeter-size animals; it represents a general cue indicative of the proximity of the nursery habitat (Paris et al., 2013). Keeping a bearing in a cardinal direction away from the coastal environment may be eased by magnetoreception, but to date few larval fish species responded to changes in the magnetic field in the laboratory (e.g., [31,32]). Stronger and most systematic orientation using polarized or direct sun light were observed in situ [9,33]. Therefore, while some larval fish may be able to sense magnetic fields, they likely use several cues and, when available, favor more directly ubiquitous signals like celestial cues; such response has been observed in several terrestrial insects [34,35].

One remarkable example of phototactic-related behavior is the ability of larval fish to use the sun as a compass to swim directionally in the open ocean at the end of their pelagic phase, even when no coastal cues are available [9]. This mechanism may help them reach coastal settlement habitat [36] but may not be present in pelagic fishes that spend their entire life cycle at sea and do not need to orient towards a specific coastal habitat. Thus, the simple question of whether the ELH stages of pelagic fishes are able to orient in the open ocean has yet to be answered. The sun is available year-round throughout the distribution of mahi-mahi [37], and appears as a solid candidate cue for the orientation of tropical, subtropical, and temperate pelagic species. Here, we use the Drifting In Situ Chamber (DISC) setup [11] in a large circular tank and lighting-control system in the laboratory to test the ability of mahi-mahi ELH stages to use the a sun-like cue as a compass. We describe the mahi-mahi swimming activity and abilities to orient to a light cue during ontogeny. 


\section{Materials and Methods}

\subsection{Ethics Statement}

The experimental protocol was approved by the University of Miami Institutional Animal Care and Use Committee, under protocol number 17-207. Every effort was made to minimize stress to experimental subjects, which is critical both ethically and for the validity of the behavior observed.

\subsection{Rearing and Handling of the Early Life History Stages of Mahi-Mahi}

The ELH stage mahi-mahi utilized in this experiment originated from a volitional spawning event of captive wild-caught mahi-mahi adults that were maintained at the University of Miami Experimental Hatchery (UMEH) facility on Virginia Key, FL, USA. Using techniques and systems described in detail in [38], the viable embryos were collected and reared at the UMEH facility in $2.4 \mathrm{~m}^{3}$ cylindrical fiberglass tanks using filtered, UV-sterilized, flow-through seawater and aquaculture larval production techniques that have proven successful for this species. Such techniques have been adapted from those which have been described for mahi-mahi and cobia Rachycentron canadum (Linnaeus, 1766) [39,40], whereby enriched rotifers (Brachionus plicatilis Müller, 1786) are used as a first feeding prey item, followed by use of enriched Artemia spp. nauplii over the course of the rearing period encompassed in this experiment.

In the morning of each experiment day, mahi-mahi ELH stages were brought from the UMEH facility to laboratory in a $30 \mathrm{~L}$ bucket filled with water from rearing environment which included live rotifers during the preflexion and flexion stages and/or Artemia spp. nauplii for later stages. The buckets were covered with aluminum foil to avoid direct exposure to the sunlight during the transport. The duration of the transport phase was minimized ( $<15 \mathrm{~min})$ to limit the stress to the individuals prior the experiments. Once in the laboratory, an aerator was installed in the main bucket, which was kept covered. The room's temperature was controlled at $26^{\circ} \mathrm{C}$, which was within the $25.5^{\circ} \mathrm{C}-27^{\circ} \mathrm{C}$ rearing temperature range to avoid to any thermal stress.

\subsection{DISC Experiment}

The behavioral data were collected with the Drifting In Situ Chamber (DISC) observational system. The design of the DISC has evolved since it was first conceived [41,42]. The detailed description of the chamber's current version is presented in [11]. In brief, the DISC is composed of a clear acrylic frame with a top and bottom plate connected at the perimeter of each plate by three vertical poles; a circular behavioral chamber is suspended between the plates and is made of a transparent acrylic bottom and 1-mm Nytrex ${ }^{\circledR}$ mesh on the sides and a closing lid. A GoPro4 ${ }^{\circledR}$ camera was placed on the bottom plate looking up into the behavioral chamber (Figure 1b). One analog compass is set on each pole within the field of view of the camera and a Hobo ${ }^{\circledR}$ environmental sensor was attached on top plate of the frame to record temperature and light measured every $30 \mathrm{~s}$ (Figure 1a). The experimental setup consisted of a $3 \mathrm{~m}^{3}$ circular tank filled with filtered seawater maintained at the room temperature $\left(26^{\circ} \mathrm{C}\right)$, in which the DISC was deployed, suspended to the ceiling with a thin line (Figure 1a). The lighting-control system is centered above the tank on the ceiling and comprises two pairs of full spectra lights to mimic sunlight (SolarcSystems ${ }^{\circledR}$ light bulbs of 2250 lumens, $300-800 \mathrm{~nm}$, with a small peak at $360 \mathrm{~nm}$ ). Within each light set, the two light sources display an angle of $60^{\circ}$ between the DISC's rotation axis and the centers of the two light sources. The two light sets are spaced by $3 \mathrm{~m}$ (i.e., $1.5 \mathrm{~m}$ on each side of the DISC's rotation axis). The opposite positioning of the light sets on the ceiling (Figure 1a,b) enable to switch the direction of the solar cue using a control box outside the experimental area (i.e., circular tank and the ceiling lighting-control system) and test for the phototaxis response and the accuracy of orientation throughout the ontogeny of mahi-mahi ELH stages. To exclude other visual cues, a completely opaque curtain (SteelGuard ${ }^{\circledR}$ ) surrounded the experimental area (Figure 1a).

A total of 79 larvae were tested, ranging from 7 to 23 days post-hatch (dph), since mahi-mahi larvae younger than $7 \mathrm{dph}$ are unable to track a visual signal [43]. All DISC deployments were 
conducted within 18 days (20 November and 7 December 2019) between 11:40 and 19:10 (EST) and followed the same procedure. The DISC's suspension line was pre-rotated to elicit a slow rotation throughout the deployment. A larva taken from the bucket with a wide-mouth transfer pipette was placed inside the DISC's behavioral chamber partially immersed. After closing and securing the lid with a cable-tie, the DISC was slowly deployed until the top of the chamber was $40 \mathrm{~cm}$ under the surface. The condition of the larva was then checked; larvae that were not swimming were replaced. Prior to onset of observations, the experimental setup was shielded, and the experimenter left the room. Each deployment lasted $12 \mathrm{~min}$ in total, with $2 \mathrm{~min}$ of acclimation time and $10 \mathrm{~min}$ of image recording. At the end of the $12 \mathrm{~min}$, the experimenter lifted the DISC, unlocked the lid, and collected the larva. The larva was then placed in a tube with a unique identifier and fast-frozen. All tested individuals were staged as preflexion $(n=16)$, flexion $(n=25)$, postflexion $(n=20)$, and early juvenile $(n=18)$ and their standard length was measured to the closest $0.01 \mathrm{~mm}$ a posteriori under a stereomicroscope mounted with a camera and connected to a laptop running Zen ${ }^{\circledR}$ software.

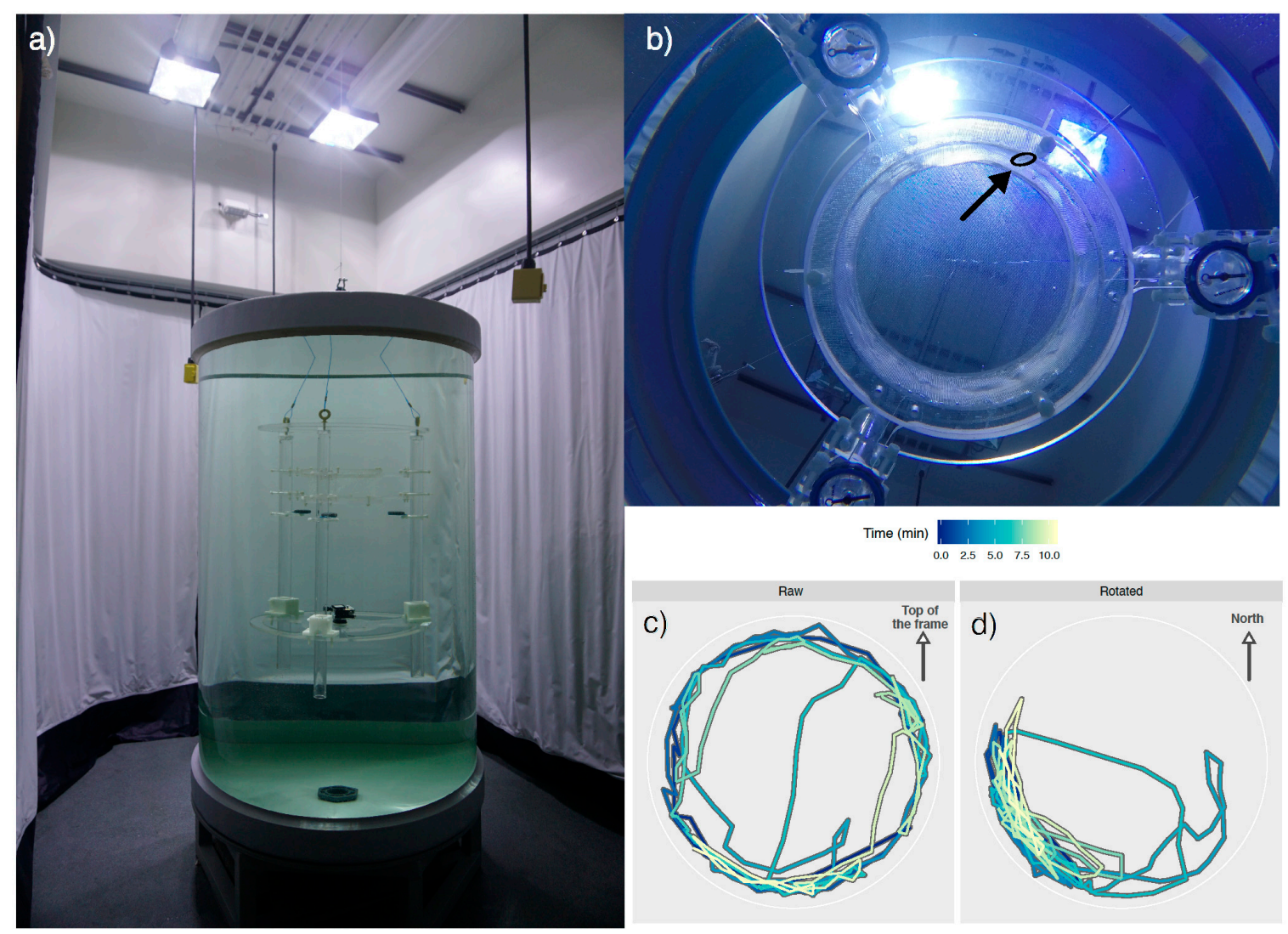

Figure 1. (a) Picture of the laboratory setup to test the orientation of early life history stages of mahi-mahi. The Drifting In Situ Chamber (DISC) was deployed in a $3 \mathrm{~m}^{3}$ circular tank, surrounded by opaque curtains. One light set of the light system is visible in the back. (b) Visual environment from inside the DISC, showing the behavioral chamber in the center and the three analog compasses on each pole. The arrow points to the position of the tested larva on the frame, inside the circle. (c) Example of raw larval track inside the chamber for $10 \mathrm{~min}$ of observation, i.e., in the frame of reference of the DISC and (d) the larval track after correcting for the rotation of the DISC during the deployment, i.e., in the cardinal frame of reference.

\subsection{Data Analysis}

DISC data were processed with the open-source software R package "discr", modified from [41]. The camera produced timelapse images at 1-s intervals, each image of 7 megapixels. The position of the larva was recorded on each image by clicking on it through a graphical user interface. Each position 
was converted to polar coordinates relative to the axis from the center of the chamber to the top of the picture (Figure 1c). The angular part of the coordinate was converted to a bearing relative to the North by subtracting the bearing of the top of the picture, recorded by the analog compasses (Figure 1d). Combined, these bearings form the trajectory of each individual during the trial and constitute the base data to detect orientation behavior [41,42].

Two levels of behavioral data can be extracted from these trajectories. At the individual level, we tested for the "directionality", i.e., the ability of a larva to maintain a cardinal bearing throughout the deployment amidst the rotation of the DISC; this was achieved with the Rayleigh test. The concentration of the larva bearings (at 1-s intervals) around the mean bearing is depicted by the Rayleigh's $r$ and its associated $p$-value [44]. Its null hypothesis is randomness in the distribution of bearings, and when the parent distribution of bearings is a circular von Mises distribution, a significant Rayleigh test proves not only non-randomness, but also concentration of bearings around the mean direction. Because the DISC rotated on its axis, each individual was characterized by the directionality and mean bearing in the frame of reference of the DISC (i.e., the top of the picture; $r_{\text {raw }}$ ) and in the cardinal reference after correcting the positions by the rotation of the DISC ( $\left.r_{\text {rotated }}\right)$. As per the requirement when dealing with data generated with the DISC [41,42], an individual is considered as "orienting" (i.e., tracking a bearing) and its mean bearing assumed relevant if and only if its directionality was significant and higher in the cardinal frame of reference than in the DISC's frame of reference $\left(r_{\text {rotated }}>r_{\text {raw }}\right)$. Individuals that did not move in the chamber were considered as not orienting, and only the $r_{\text {rotated }}$ (hereafter $r$ ) was used for subsequent analyses.

The swimming speed of an individual can be influenced by the sampling methodology [45]. Here we measured the swimming speeds in $\mathrm{cm} \mathrm{s}^{-1}$ and in body length per second (BL s${ }^{-1}$ ) based on the average displacement of the larva in the chamber at each 1-s interval. These swimming speeds are therefore conservative estimates since the larvae may not swim linearly through each 1-s interval. Even if an individual with strong swimming abilities significantly tracked a directional cue, it may display a lower directionality due to the spatial constraint of the chamber. We therefore produced a metric of orientation ability, the "directionality competence" $\left(r_{\mathrm{BL}}\right)$, that is comparable throughout the ontogeny of the species by scaling the directionality by the swimming speed in the chamber, in $\mathrm{BL} \mathrm{s}^{-1}$. The distribution of the directionalities $\left(r\right.$ and $\left.r_{\mathrm{BL}}\right)$ throughout the ontogeny of the species was then compared among development stages, size, age and swimming speed (in $\mathrm{cm} \mathrm{s}^{-1}$ and in BL s${ }^{-1}$ ) using linear regressions and analysis of variance (ANOVA or the non-parametric Kruskal-Wallis (KW) test when assumption of homoscedasticity of the residuals was not met) and post hoc pairwise tests (pairwise t-test for ANOVA and pairwise Wilcoxon for KW).

At the population level (i.e., testing for common bearing among a population of larvae), orientation metrics were computed with significantly orienting individuals only and compared by stage, size, and age. Here, the directionality becomes the "precision of orientation" (i.e., the concentration of individual mean bearings around the population's mean bearing) and the Rayleigh's test assesses whether all individuals followed the same directional cue (e.g., a cardinal direction or the light direction). The distribution of the bearings of each subset was compared with a uniform and a von Mises distribution to test for the absence or presence of a collective bearing, respectively, with Watson's tests [46]. In addition to the orientation relative to the cardinal direction, the same tests were used to detect a response regarding the (changing) light direction. Differences in orientation among stages were tested with the Wallraff test [44].

To assess the effect of the two light fixtures of each light sets as potential separated light sources for the individual tested, we computed the orientation of the individual tested with regard to (1) the mean direction between the two light sources; (2) the mean direction of the left light or (3) of the right light source; (4) the mean direction of left source when the 1st light set was on, and the mean direction of the right source when the 2nd light set was on; (5) the mean direction of right light source when the 1st light set was on and mean direction of the right light source when the 2nd light set was on; and (6) by tracking a single source following the individual preferences. The preference to a 
specific light source within deployment was defined as "left preference" when the individual's mean bearing was within $180^{\circ}$ from the mean direction between the two light sources in the anticlockwise direction, and "right preference" otherwise. For each deployment, the reference direction used to correct the bearing was set as the mean direction of the left light source for the larvae and juveniles with a "left preference", and to the mean direction of the right light source otherwise. We then compared the statistics of the resulting distributions of bearings with the Rayleigh's and Wallraff's tests to detect if specific preferences emerged toward one of the above six different orientation scenarios among deployments.

All analyses were conducted using the R software [47], with the packages "circular v0.4.93" [48] for circular statistics and "tidyverse v1.3.0" [49], for data management and graphics.

\subsection{Data Availability}

Data for this article may be accessed through the Gulf of Mexico Research Initiative Information and Data Cooperative (GRIIDC) available at https://data.gulfresearchinititative.org, DOI: 10.7266/HZB203BM. The software to process the DISC data is open-source released under the GNU General Public License v3.0 and available at www.github.com/jiho/discr.

\section{Results}

A total of 67 out of 79 individuals were deployed successfully in the DISC. The mortality during the trials decreased for larger larvae, with 19\%, 37\%, 5\%, and 0\% mortality for the preflexion $\left(n_{\text {dead }}=3\right)$, flexion $\left(n_{\text {dead }}=9\right)$, postflexion $\left(n_{\text {dead }}=1\right)$, and early juvenile $\left(n_{\text {dead }}=0\right)$ stages, respectively. Swimming speed in the chamber increased with size $\left(\mathrm{R}^{2}{ }_{\text {adj }}=0.576, F=90.78, p=5.88 \times 10^{-14}\right)$, and thus with development stages, ranging from $0.26 \pm 0.12 \mathrm{~cm} \mathrm{~s}^{-1}$ in preflexion larvae to $1.62 \pm 0.8 \mathrm{~cm} \mathrm{~s}^{-1}$ in juveniles with a large improvement in swimming abilities observed between the flexion and postflexion stages, both in terms of swimming speed (from $0.32 \pm 0.19 \mathrm{~cm} \mathrm{~s}^{-1}$ to $1.04 \pm 0.60 \mathrm{~cm} \mathrm{~s}^{-1}$; Figure $2 \mathrm{a}$ ) and in swimming speed relative to body size (from $0.48 \pm 0.30 \mathrm{BL} \mathrm{s}^{-1}$ to $0.80 \mathrm{BL} \mathrm{s}^{-1}$, respectively; Figure $2 \mathrm{~b}$ ).
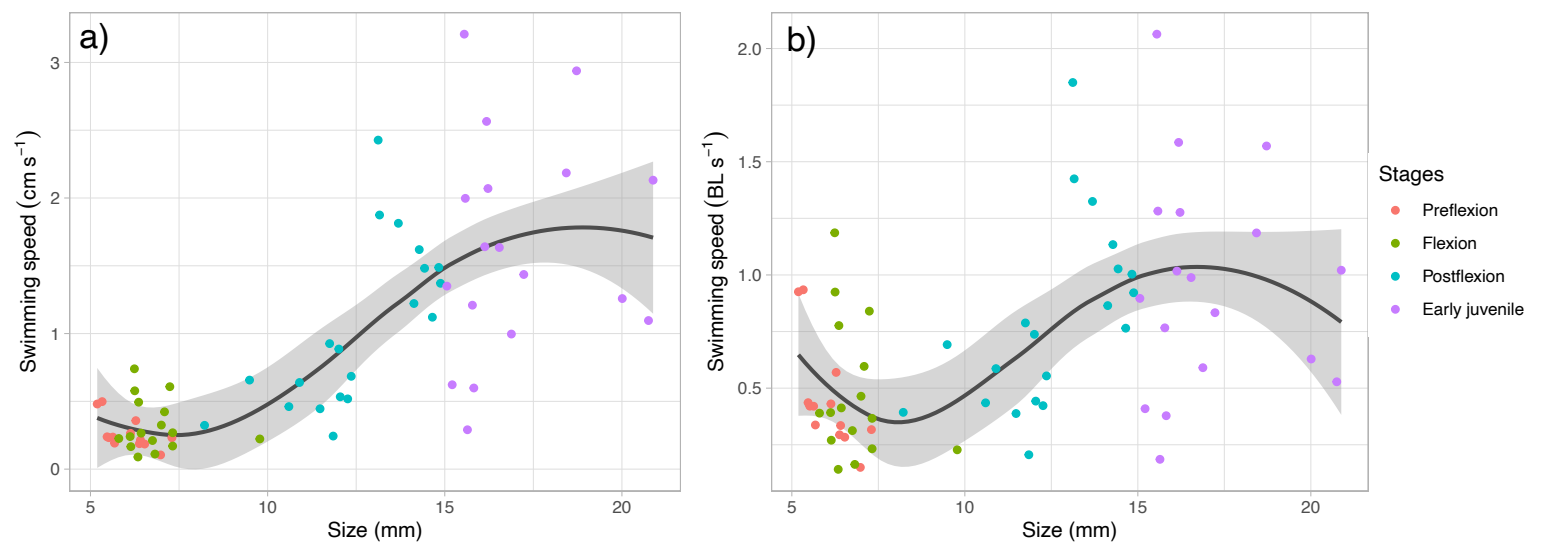

Figure 2. Ontogeny of the swimming speeds by size (a) in $\mathrm{cm} \mathrm{s}^{-1}$ and (b) in body length $\mathrm{s}^{-1}\left(\mathrm{BL} \mathrm{s}^{-1}\right)$. The colors indicate the four development stages tested. The curve shows the loess fitting with the confidence interval in the gray shading.

The proportion of individuals swimming non randomly was $84.6 \%, 93.8 \%, 100 \%$, and $83.3 \%$ for the four development stages tested, respectively, showing no clear ontogenetic pattern. Directionality also showed no relationship with size (linear regression, $\mathrm{F}_{1-65}=0.46, p=0.50$ ) nor with swimming speed when considering all individuals (linear regression, $\mathrm{F}_{1-65}=2.45, p=0.12$ ). When focusing on the individuals that oriented, the directionality becomes negatively correlated with both size and swimming speed, with a stronger relationship with swimming speed $\left(\mathrm{R}^{2}\right.$ adj $=0.11, F=6.57, p=0.014$ and $\mathrm{R}^{2}$ adj $=0.29, F=19.53, p=6.19 \times 10^{-5}$, respectively; Figure 3). 

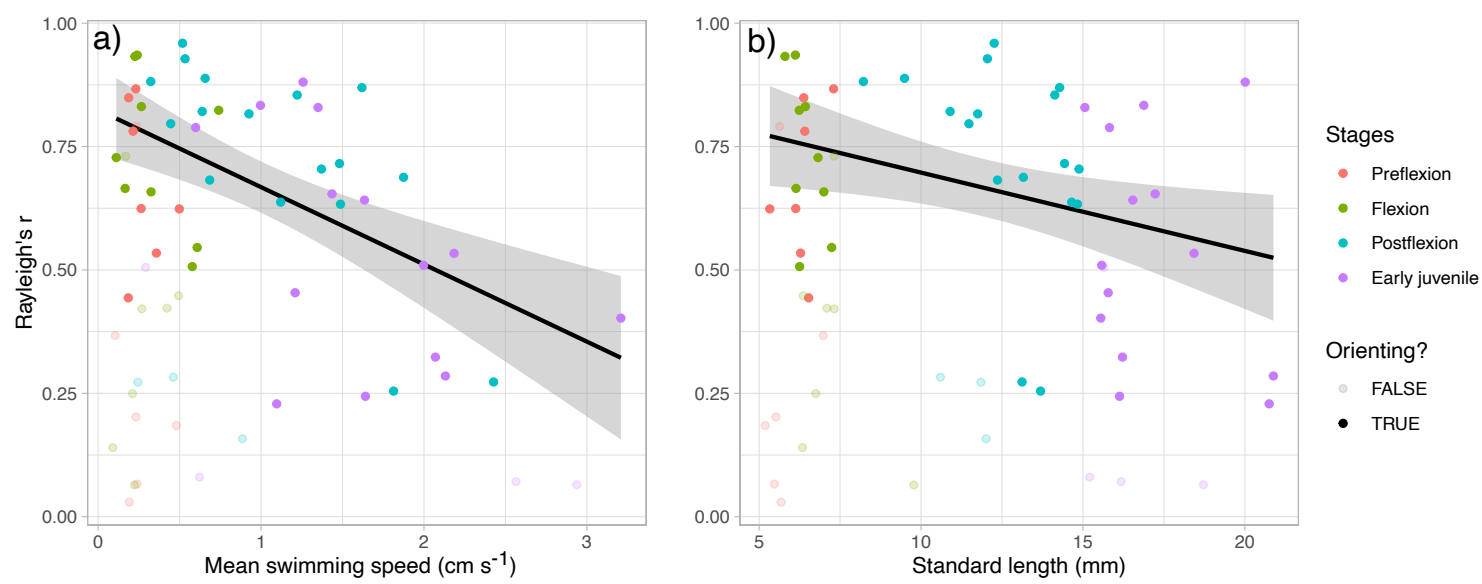

Figure 3. Distribution of the directionality of all individual larvae (Rayleigh's $r$ ) as function of their mean swimming speed in the chamber (a) and standard length (b), by development stage. The line and shaded area highlight the significant linear relationship (and confidence interval) in the orienting individuals only. Larvae that did not orient significantly (i.e., with $r_{\text {raw }}<r_{\text {rotated }}$ ) are shown as faded dots.

The Rayleigh's $r$ is typically used to assess directionality among individuals of the same development stages [44]. However, it cannot be a comparative measure of directionality between larvae of different stages and thus swimming speeds. Indeed, there was no difference of Rayleigh's $r$ among stages (Fligner, $\mathrm{Chi}=0.61, p=0.90 ; \mathrm{KW}, \mathrm{Chi}=5.97, p=0.11$; Figure 4). The negative correlation between the size or the swimming speed and the directionality may thus indicate that the directionality is overestimated in small and slow moving individuals and conversely, underestimated in large, fast swimmers. To better depict the ontogeny of orientation capabilities, we scaled the directionality $\left(r_{B L}\right)$ by the individuals' swimming speed relative to their body size $\left(\mathrm{U}_{\mathrm{BL}}\right)$ :

$$
r_{B L}=\frac{r}{U_{B L}}
$$

The scaled directionality represents the "directionality competence" and is the lowest for preflexion larvae, increases during the flexion and postflexion stages, after which it remains stable (among stages comparisons tests: Bartlett, $K^{2}=4.37, p=0.22$; ANOVA, $F=5.0, p=0.003$; Shapiro, $W=0.98, p=0.32$; posthoc pairwise $t$-test with Benjamini and Hochberg correction for multiple testing, $p<0.05$ between the pairs preflexion vs. postflexion and juvenile, and between flexion vs. postflexion; Figure 4).
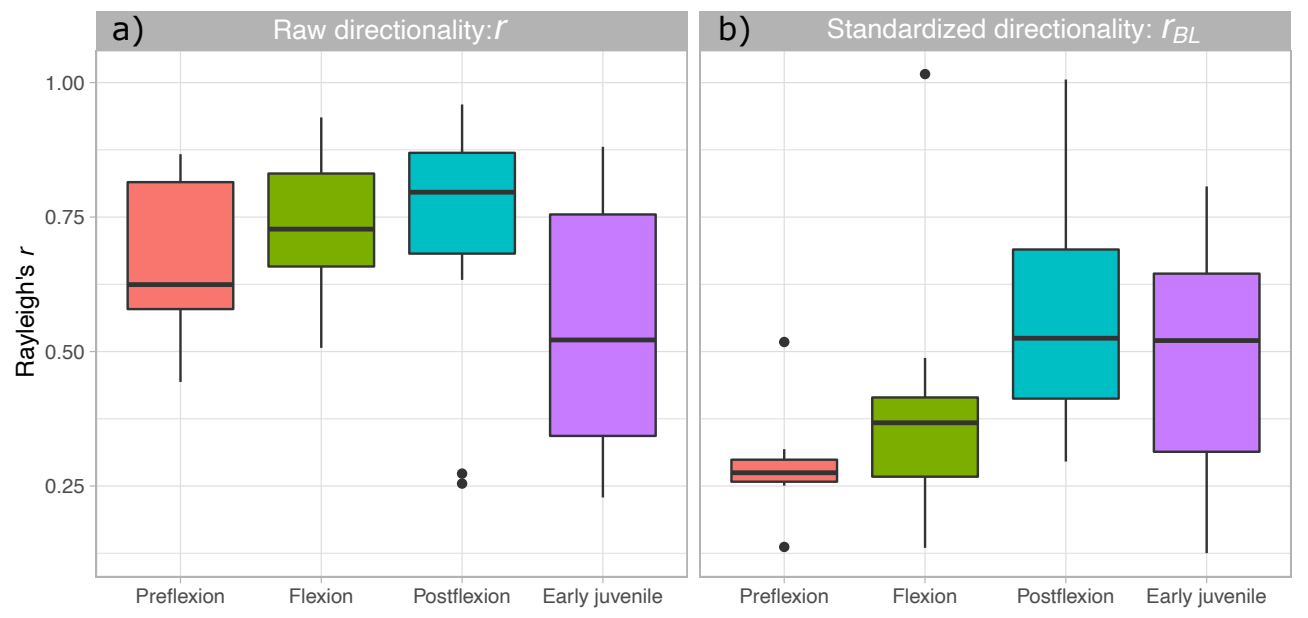

Figure 4. Ontogeny of directionality considering (a) the raw Rayleigh's $r$ directionality and (b) the directionality competence. 
All ELH stages combined display a bimodal cardinal orientation (Figure 5a), with a distribution different from uniform (Watson's test statistics $=0.26, p<0.01$ ) and von Mises distributions (Watson's test statistics $=0.29, p<0.01$ ). When correcting for the mean direction of the manipulated light cue (i.e., the mean direction between the two light sources), the distribution remains different from uniform (Watson's test statistics $=1.88, p<0.01$ ) and von Mises (Watson's test statistics $=0.13,0.01<p<0.05$ ), yet with the emergence of a clear positive phototactic orientation (Figure 5b). Exploring the orientation per development stage shows that preflexion individuals are actually unable to efficiently track the light cue (for uniform: Watson's test statistics $=0.08, p>0.10$; for von Mises: Watson's test statistics $=0.58, p>0.05$ ), while individuals in the flexion and older stages do (for uniform: all Watson's test statistics $>0.46$ and all $p>0.10$; for von Mises: all Watson's test statistics $<0.082$ and all $p>0.10$; Figure $6 \mathrm{a}, \mathrm{b})$. When omitting the preflexion stage, the distribution of the orientation towards the light source also becomes not significantly different from a von Mises distribution, suggesting a strong, population-level phototaxis response (Watson's test statistics $=0.054, p>0.10$ ). In most cases (58 over 67 successful deployments), the distribution of swimming directions within deployments are random, just like the distribution of mean swimming directions among deployments (Supplementary Figure S1; Watson's test statistics, all $p>0.10)$.

With regard to the technical issue of having two light sources in each light set, we found no preference to one of the four light sources from the two light sets. Considering the scenario 4 (i.e., the left light source in the first light setting and the right light source in the second setting) or the scenario 5 (inverse to scenario 4) degraded the precision of orientation towards the light cue (Rayleigh tests, mean bearings of $356.7^{\circ}, r=0.74, p=1.40 \times 10^{-11}$ and $350.7^{\circ}, r=0.67, p=5.39 \times 10^{-10}$, respectively). Overall, the mean bearing of all individual tested was closer to the left light source among all deployments (Rayleigh tests, mean bearing relative to the left light source (scenario 2): $23.9^{\circ}$, mean bearing relative to the right light source (scenario 3): $323.9^{\circ}$, both $r=0.81$ and $p<2.34 \times 10^{-13}$ ) but the narrowest positive phototaxis occurred when considering the preferred light source per deployment (scenario 6; Rayleigh test, mean bearing of $\left.1.5^{\circ}, r=0.88, p=6.40 \times 10^{-15}\right)$. The distribution of bearings towards the preferred light source (scenario 6) is significantly different from a uniform distribution (Watson test's statistic $=2.30, p<0.01$ ) and not different from the bearings' distribution towards the mean light cue (scenario 1; Wallraff test, $\mathrm{Chi}^{2}=0.05, p=0.82$ ), confirming a positive phototaxis.

Exploring the orientation per stage shows that flexion and postflexion displayed a slightly higher precision towards the preferred light source (scenario 6; flexion, mean bearing $=8.2^{\circ}, r=0.94, p=10^{-10}$; postflexion, mean bearing $=355.8^{\circ}, r=0.93, p=3 \times 10^{-7}$ ) than towards the mean direction of the light cue (scenario 1; flexion: mean bearing $=344.3^{\circ}, r=0.89, p=6.4 \times 10^{-5}$; postflexion, mean bearing $=351.3^{\circ}$, $r=0.92, p=3.3 \times 10^{-7}$ ). Interestingly, the flexion and postflexion stages maintained an angle relative to the light source (Figure $6 \mathrm{~b}, \mathrm{c}$ ), while early juveniles accurately tracked the exact direction of a single (i.e., preferred) light source (scenario 6, mean bearing $=359.2^{\circ}, r=0.97, p=9.5 \times 10^{-7}$; versus mean bearing $359.8^{\circ}, r=0.88, p=9 \times 10^{-7}$ for the scenario 1 towards the mean direction of the light cue; Figure 6). No dial pattern of orientation towards the light cue emerged for any stages (Supplementary Figure S2). 




Relative to the light direction

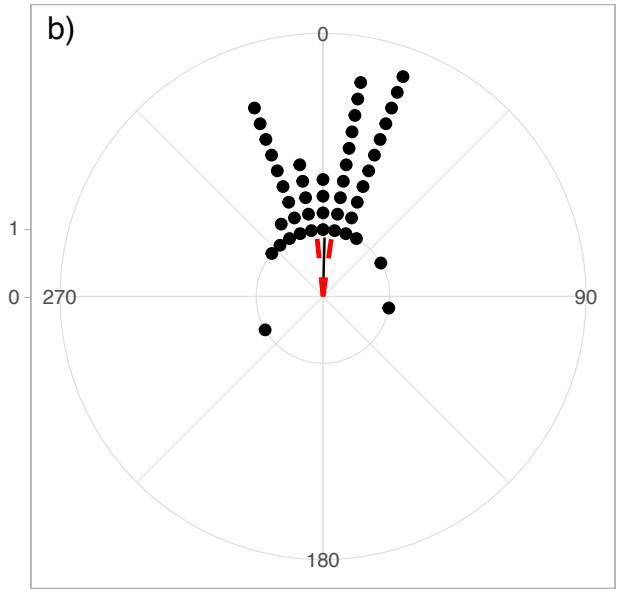

Figure 5. Mahi-mahi orientation. (a) Circular plots of orientation in the cardinal frame of reference; and (b) towards the manipulated light cue in degrees from the preferred light direction for all significantly orienting individuals $(n=47)$.

a) Relative to the cardinal direction
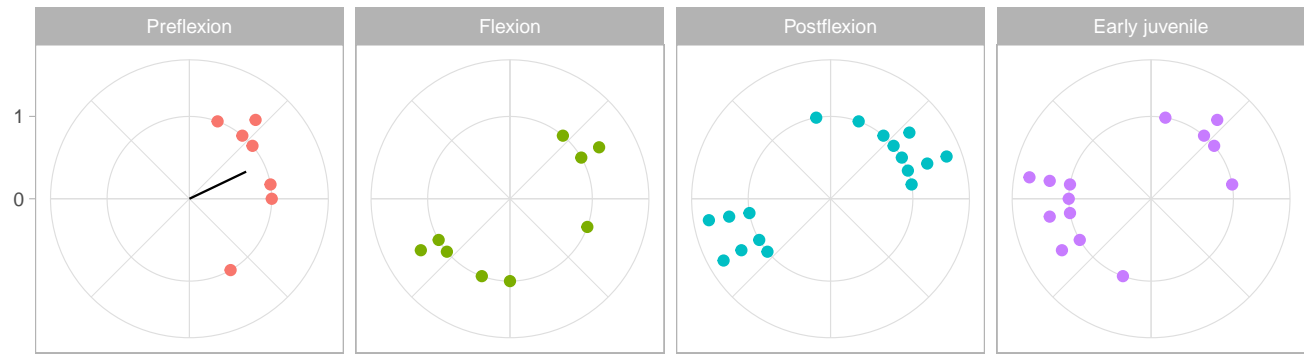

b) Relative to the mean light direction
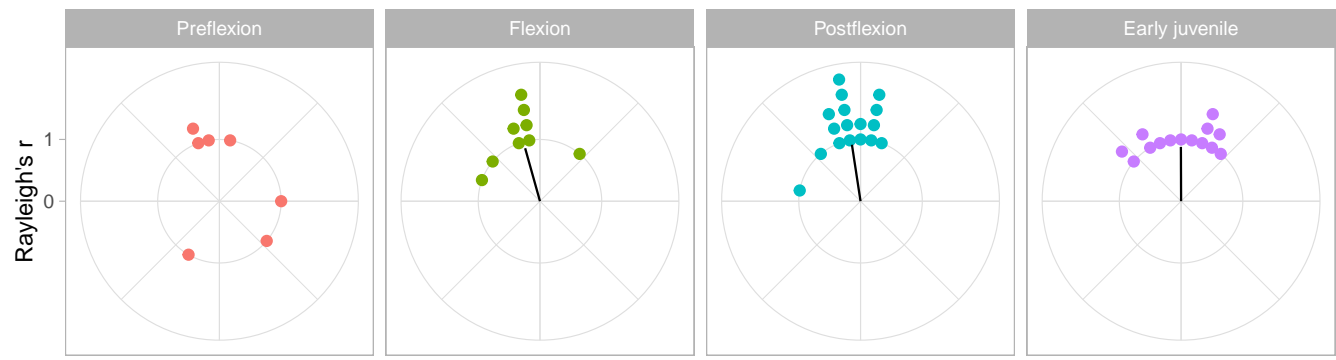

c) Relative to the preferred light direction


Figure 6. Mahi-mahi orientation by developmental stages. (a) Circular plots of the orientation towards a cardinal direction (in degree from the North); (b) orientation towards the center of the light system (in degrees from the light source), by development stage; and (c) orientation towards the preferred light source (in degrees from the center of the light source). Each dot represents one larva observed for $10 \mathrm{~min}$. Mean larval bearings over $10 \mathrm{~min}$ are binned over 10 degrees. Significant mean bearing is shown with a radius (solid line), which length is proportional to the precision of orientation. 


\section{Discussion}

Work investigating the phototaxis in fish larvae (e.g., [50]) has so far focused on the phototaxis per se, away from or towards the source of light and its intensity, and characterized as either attraction or repulsion [5]. Orientation abilities, however, received less emphasis. Here, by combining aquaculture larval rearing facilities for marine fish and an orientation behavioral laboratory setup with controlled environmental conditions, we described the ontogeny of orientation abilities and the swimming performances of mahi-mahi ELH stages. Unsurprisingly, we found that swimming performance improved with size, yet not linearly: notable improvements occurred during the postflexion stage, with poor swimming at preflexion, and flexion stages, while the largest postflexion and early juvenile stages were faster (Figure 2a) and more efficient swimmers (Figure 2b). This pattern is in line with the general increase of swimming capabilities with the ossification of the skeleton and the myomeres' development during postflexion [51,52], which is also displaying the highest variability in swimming capabilities [52].

More interesting was that the rotating design of the DISC [41,42] enabled the quantification of orientation relative to the light's direction. We show that preflexion stages are poorly directional and do not orient toward a common direction nor in response to a directional light stimulus. However, mahi-mahi larvae start orienting at the flexion stage, with a positive phototactic behavior that persists throughout the early juvenile stage (Figure 6). Mahi-mahi larvae hatch with immature eye and have low visual acuity before flexion of the notochord, and such age-dependent visual function has been recently demonstrated in optomotor response potentially related to the development of the retina during the flexion stage between 7 and $10 \mathrm{dph}$ [43]. Our results indicate that the development of the anatomical visual acuity previously detected during notochord flexion translates into a direct improvement of their orientation capabilities, highlighting the bond between the visual abilities and orientation capabilities in mahi-mahi ELH stages. Regarding the swimming performance, size appears as a better predictor than age, with a threshold above $10 \mathrm{~mm} \mathrm{SL}$, as in most coral reef species [53]. These distinct behavioral trends lead us to assess the "directionality competence" in addition of the traditional directionality, in particular when comparing different development stages. The directionality competence highlights how mahi-mahi larvae start orienting using an external stimulus before the rapid improvement of their swimming capabilities (Figures 2 and 6), suggesting an ecological advantage related to early orientation.

To orient, mahi-mahi ELH stages need to use external and directional cues, as other fish larvae do [54]. Mahi-mahi spend their entire life cycle in a pelagic ocean environment, where coastal cues are not available, and do not display any preference for water with dimethyl sulfide (DMS), a chemical observed to be an orientation cue for coastal fish species [55]. Here we manipulated a single but universal cue, light, in the absence of environmental cues other than the magnetic field, conclusions can only be driven regarding cardinal versus phototactic orientation responses. Our results show no consistent orientation towards a cardinal direction but a marked attraction and accurate orientation toward the light direction at all stages, except for preflexion larvae. The precision of orientation relatively to the light cue increases throughout ontogeny until becoming exceptionally accurate at the early juvenile stage, once the preferred light source has been distinguished, in line with the development of the directionality competence (Figures 4-6). From the flexion stage, mahi-mahi are thus able to use a directional light source coming from above the surface, such as the sun's light observed through Snell's window in the ocean [56], and orient relatively to it. The ability of late stage larvae of coastal species to use the sun compass has been demonstrated in situ [9,57], and in laboratory as a time-compensated compass [36]; our results thus indicate that the ELH stages of the pelagic species Coryphaena hippurus likely possess similar abilities.

The ontogeny of behavior, with the early emergence of orientation abilities may enhance optimal foraging at fine scale [58]. Orienting using external cues such as the sun enables movement following a Levy flight motion (or correlated biased random walk; [59]) to efficiently search for prey during the day by minimizing the foraging in areas/water masses that have already been explored, as observed in many foraging species [60]. Altogether, the early abilities of mahi-mahi larvae to orient, even before 
the improvement of swimming performance, could thus explain their fastest initial growth over any other marine fish species [38,61]. Following the critical period of first-feeding, the transition from the flexion to the postflexion stage may thus be another period of disproportionate importance, since the development of behavioral abilities is key for optimal prey selection during the transition between food sources [62].

The presence of a strong and systematic response observed in all but the preflexion stage suggests that the setup used was efficient at addressing the orientation ability towards the light's direction. Still, testing only reared larvae may have differed from wild-caught individuals, but here, collecting live mahi-mahi larvae is not an option due to their scarcity and exclusively pelagic distribution. However, light is one of the most primitive cues detected during the ELH of any organism [63] and, based on our observation, it also appears as an innate behavior in reared mahi-mahi. Another potential limitation could have arisen from the light setup that had two sets of two light sources per light set, which could have confused the individuals compared to the detection of the sun's disk. However, the results indicate that all individuals (except preflexion larvae) "picked" a single light source and then oriented relative to its direction, further confirming that mahi-mahi ELH stages possess the ability to exploit the sun' direction as a compass in the open ocean.

In conclusion, this experiment demonstrates that swimming capabilities should be considered when assessing the performance of orientation throughout ontogeny. We thus developed the "directionality competence" metric that allows comparison of orientation abilities among stages, size or age. Just like coastal species with a bipartite life cycle, the early life stages of pelagic species may possess the ability to orient and swim directionally in the open ocean since they can track the direction of a solar cue. Current methods used for larval rearing in aquaculture settings (e.g., at the UMEH; [4]) manipulate light levels and photoperiods to increase growth and subsequently survival throughout the early life history stages. Aside from increasing the understanding of orientation and swimming abilities in an ecological context, the present study provides further insights that support the relevance of these strategies. A finer sampling throughout ontogeny would enable refinement of the chronology of the directionality competence, in particular during the transition from the flexion to the postflexion stages when rapid improvements take place. The laboratory conditions enabled control of environmental cues; the next step is to test the sun compass with the DISC deployed in the wild.

Supplementary Materials: The following are available online at http://www.mdpi.com/2673-1924/1/4/17/s1, Figure S1: Mean swimming direction for all tested individuals, Figure S2: Mean orientation relative to the light direction for significantly orienting individuals only per time of day and development stages.

Author Contributions: Conceptualization, R.F., E.J., J.S., D.B., M.G., and C.B.P.; methodology, R.F., E.J., P.D., A.S., J.S., and C.B.P.; formal analysis, R.F., E.J., A.S., and P.D.; investigation, R.F. and C.B.P.; data curation, R.F.; writing—original draft preparation, R.F.; writing—review and editing, R.F., E.J., P.D., A.S., J.S., D.B., M.G., and C.B.P.; visualization, R.F. and C.B.P.; supervision, R.F., C.B.P., and M.G.; project administration, M.G. and C.B.P.; funding acquisition, M.G. and C.B.P. All authors have read and agreed to the published version of the manuscript.

Funding: This research was made possible by a grant from The Gulf of Mexico Research Initiative RECOVER 2, No. SA-1520 (Relationship of effects of cardiac outcomes in fish for validation of ecological risk) and C-IMAGE III, No. SA 18-16. The DISC's development was funded by the NSF-OCE 1459156 to C.B.P.

Acknowledgments: The authors would like to thank Macy Sherman and Adèle Fleury for their help with the DISC experiment. Martin Grosell holds a Maytag Chair of Ichthyology. Data are publicly available through the Gulf of Mexico Research Initiative Information \& Data Cooperative (GRIIDC) at https://data.gulfresearchinitiative.org (DOI:10.7266/HZB203BM).

Conflicts of Interest: The authors declare no conflict of interest.

\section{References}

1. Ragatz, L.; Jiang, Z.Y.; Bauer, C.E.; Gest, H. Macroscopic phototactic behavior of the purple photosynthetic bacterium Rhodospirillum centenum. Arch Microbiol. 1995, 163, 1-6. [CrossRef] [PubMed]

2. Masuda, R.; Tsukamoto, K. Morphological development in relation to phototaxis and rheotaxis in the striped jack, Pseudocaranx dentex. Mar. Freshw. Behav. Physiol. 1996, 28, 75-90. [CrossRef] 
3. Ina, Y.; Sakakura, Y.; Yamada, T.; Kumon, K.; Eba, T.; Konishi, J.; Takashi, T.; Gen, K.; Tanaka, Y.; Hashimoto, H. Development of phototaxis in the early life stages of Pacific bluefin tuna Thunnus orientalis. Fish. Sci. 2017, 83, 537-542. [CrossRef]

4. Partridge, G.; Benetti, D.; Stieglitz, J.; Hutapea, J.; McIntyre, A.; Chen, B.; Hutchinson, W.; Scholey, V. The effect of a 24-hour photoperiod on the survival, growth and swim bladder inflation of pre-flexion yellowfin tuna (Thunnus albacares) larvae. Aquaculture 2011, 318, 471-474. [CrossRef]

5. Nicolaisen, O.; Bolla, S. Behavioural responses to visual environment in early stage Atlantic cod Gadus morhua L. larvae. Aquac Res. 2016, 47, 189-198. [CrossRef]

6. Chen, X.; Engert, F. Navigational strategies underlying phototaxis in larval zebrafish. Front. Syst. Neurosci. 2014, 8, 1-13. [CrossRef]

7. Leis, J.M. Are larvae of demersal fishes plankton or nekton? Adv. Mar. Biol. 2006, 51, 57-141. [CrossRef]

8. Irisson, J.; Paris, C.B.; Leis, J.M.; Yerman, M.N. With a little help from my friends: Group orientation by larvae of a coral reef fish. PLOS ONE 2015, 10,1-14. [CrossRef]

9. Faillettaz, R.; Blandin, A.; Paris, C.B.; Koubbi, P.; Irisson, J.-O. Sun-compass orientation in mediterranean fish larvae. PLoS ONE 2015, 10, e0135213. [CrossRef]

10. Leis, J.; Siebeck, U.; Hay, A.; Paris, C.; Chateau, O.; Wantiez, L. In situ orientation of fish larvae can vary among regions. Mar. Ecol. Prog. Ser. 2015, 537, 191-203. [CrossRef]

11. Paris, C.B.; Atema, J.; Irisson, J.-O.; Kingsford, M.; Gerlach, G.; Guigand, C.M. Reef odor: A wake up call for navigation in reef fish larvae. PLoS ONE 2013, 8, e72808. [CrossRef] [PubMed]

12. Leis, J.M. Ontogeny of behaviour in larvae of marine demersal fishes. Ichthyol. Res. 2010, 57, 325-342. [CrossRef]

13. Leis, J.M.; Hay, A.C.; Clark, D.L.; Chen, I.S.; Shao, K.T. Behavioral ontogeny in larvae and early juveniles of the giant trevally (Caranx ignobilis) (Pisces: Carangidae). Fish. Bull. 2004, 104, 401-414.

14. Leis, J.M.; Hay, A.C.; Trnski, T. In situ ontogeny of behaviour in pelagic larvae of three temperate, marine, demersal fishes. Mar. Biol. 2006, 148, 655-669. [CrossRef]

15. Irisson, J.-O. Approche Comportementale de la Dispersion Larvaire en Milieu Marin. Sciences du Vivant [q-bio]. Ecole pratique des hautes études-EPHE PARIS, 2008. HAL Id: tel-00344625. Available online: https://tel.archives-ouvertes.fr/file/index/docid/344625/filename/THESE-Irisson.pdf (accessed on 1 October 2020).

16. Staaterman, E.; Paris, C.B. Modelling larval fish navigation: The way forward. ICES J. Mar. Sci. 2014, 71, 918-924. [CrossRef]

17. Faillettaz, R.; Paris, C.B.; Irisson, J.-O. Larval fish swimming behavior alters dispersal patterns from marine protected areas in the North-Western Mediterranean Sea. Front. Mar. Sci. 2018, 5, 1-12. [CrossRef]

18. Staaterman, E.; Paris, C.B.; Helgers, J. Orientation behavior in fish larvae: A missing piece to Hjort's critical period hypothesis. J. Theor. Biol. 2012, 304, 188-196. [CrossRef]

19. Faillettaz, R.; Durand, E.; Paris, C.B.; Koubbi, P.; Irisson, J.O. Swimming speeds of Mediterranean settlement-stage fish larvae nuance Hjort's aberrant drift hypothesis. Limnol. Oceanogr. 2018, 63, 509-523. [CrossRef]

20. Bode, M.; Leis, J.M.; Mason, L.B.; Williamson, D.H.; Harrison, H.B.; Choukroun, S.; Jones, G.P. Successful validation of a larval dispersal model using genetic parentage data. PLoS Biol. 2019, 17, e3000380. [CrossRef]

21. Leis, J.J.M. Behaviour as input for modelling dispersal of fish larvae: Behaviour, biogeography, hydrodynamics, ontogeny, physiology and phylogeny meet hydrography. Mar. Ecol. Prog. Ser. 2007, 347, 185-193. [CrossRef]

22. Swearer, S.E.; Treml, E.A.; Shima, J.S. A review of biophysical models of marine larval dispersal. In Oceanography and Marine Biology; CRC Press: Boca Raton, FL, USA, 2019. [CrossRef]

23. Selden Burke, J.; Tanaka, M.; Seikai, T. Influence of light and salinity on behaviour of larval Japanese flounder (Paralichthys olivaceus) and implications for inshore migration. Neth. J. Sea Res. 1995, 34, 59-69. [CrossRef]

24. Champalbert, G.; Le Direach-Boursier, L. Influence of light and feeding conditions on swimming activity rhythms of larval and juvenile turbot Scophthalmus maximus L.: An experimental study. J. Sea Res. 1998, 40, 333-345. [CrossRef]

25. Blaxter, B.Y.J.H.S. Visual thresholds and spectral sensitivity of herring larvae. J. Exp. Biol. 1968, 48, 39-53.

26. Hartmann, S.; Vogt, R.; Kunze, J.; Rauschert, A.; Kuhnert, K.-D.; Wanzenböck, J.; Lamatsch, D.K.; Witte, K. Zebrafish larvae show negative phototaxis to near-infrared light. PLoS ONE 2018, 13, 1-16. [CrossRef] 
27. Montgomery, J.C.; Tolimieri, N.; Haine, O.S. Active habitat selection by pre-settlement reef fishes. Fish Fish. 2001, 2, 261-277. [CrossRef]

28. Simpson, S.D.; Meekan, M.; Montgomery, J.; McCauley, R.; Jeffs, A. Homeward sound. Science (80-) 2005, 308, 221. [CrossRef]

29. Teodósio, M.A.; Paris, C.B.; Wolanski, E.; Morais, P. Biophysical processes leading to the ingress of temperate fish larvae into estuarine nursery areas: A review. Estuar. Coast. Shelf Sci. 2016, 183, 187-202. [CrossRef]

30. Atema, J.; Gerlach, G.; Paris, C.B. Sensory biology and navigation behavior of reef fish larvae. In Ecology of Fishes on Coral Reefs; Mora, C., Ed.; Cambridge University Press: Cambridge, UK, 2015; pp. 3-15.

31. O'Connor, J.; Muheim, R. Pre-settlement coral-reef fish larvae respond to magnetic field changes during the day. J. Exp. Biol. 2017, 220, 2874-2877. [CrossRef]

32. Cresci, A.; Paris, C.B.; Foretich, M.A.; Durif, C.M.; Shema, S.D.; O’Brien, C.; Vikebø, F.B.; Skiftesvik, A.-B.; Browman, H.I. Atlantic haddock (Melanogrammus aeglefinus) larvae have a magnetic compass that guides their orientation. iScience 2019, 19, 1173-1178. [CrossRef]

33. Berenshtein, I.; Kiflawi, M.; Shashar, N.; Wieler, U.; Agiv, H.; Paris, C.B. Polarized light sensitivity and orientation in coral reef fish post-larvae. PLOS ONE 2014, 9, e88468. [CrossRef]

34. Kheradmand, B.; Nieh, J.C. The role of landscapes and landmarks in bee navigation: A review. Insects 2019, 10, 342. [CrossRef] [PubMed]

35. Riveros, A.J.; Srygley, R.B. Magnetic compasses in insects. In Encycopedia of Animal Behavior, 2nd ed.; Elsevier Ltd.: Amsterdam, The Netherlands, 2019; pp. 588-597.

36. Mouritsen, H.; Atema, J.; Kingsford, M.J.; Gerlach, G. Sun compass orientation helps coral reef fish larvae return to their natal reef. PLoS ONE 2013, 8, e66039. [CrossRef] [PubMed]

37. Palko, B.J.; Beardsley, G.L.; Richards, W.J. Synopsis of the Biological Data on Dolphin-Fishes, Coryphaena Hippurus Linnaeus and Coryphaena Equiselis Linnaeus; FAO Fisheries Synopsis Report; U.S. Department of Commerce: Washington, DC, USA, 1982; Volume 130, p. 34.

38. Stieglitz, J.D.; Hoenig, R.H.; Kloeblen, S.; Tudela, C.E.; Grosell, M.; Benetti, D.D. Capture, transport, prophylaxis, acclimation, and continuous spawning of Mahi-mahi (Coryphaena hippurus) in captivity. Aquaculture 2017, 479, 1-6. [CrossRef]

39. Kraul, S. Larviculture of the Mahimahi Coryphaena hippurus in Hawaii, USA. J. World Aquac. Soc. 1993, 24, 410-421. [CrossRef]

40. Benetti, D.D.; Sardenberg, B.; Welch, A.; Hoenig, R.; Orhun, M.R.; Zink, I. Intensive larval husbandry and fingerling production of cobia Rachycentron canadum. Aquaculture 2008, 281, 22-27. [CrossRef]

41. Irisson, J.-O.; Guigand, C.; Paris, C.B. Detection and quantification of marine larvae orientation in the pelagic environment. Limnol. Oceanogr. Methods 2009, 7, 664-672. [CrossRef]

42. Paris, C.B.; Guigand, C.M.; Irisson, J.; Fisher, R.; Alessandro, D. Orientation with no frame of reference (OWNFOR): A novel system to observe and quantify orientation in reef fish larvae. In Caribbean Connectivity: Implications for Marine Protected Area Management, Proceedings of the Special Symposium: 59th Annual Meeting of the Gulf and Caribbean Fisheries Institute. Belize city, Belize, 9-11 November 2006; Grober-Dunsmore, R., Keller, B.D., Eds.; Marine Sanctuaries Conservation Series NMSP- 08-xx. U.S. Department of Commerce, National Oceanic and Atmospheric Administration, National Marine Sanctuary Program: Silver Spring, MD, USA, 2008; pp. 54-64.

43. Magnuson, J.T.; Stieglitz, J.D.; Garza, S.A.; Benetti, D.D.; Grosell, M.; Roberts, A.P. Development of visual function in early life stage mahi-mahi (coryphaena hippurus). Mar. Freshw. Behav. Physiol. 2020, in press. [CrossRef]

44. Batschelet, E. Circular Statistics in Biology; Academic Press: London, UK, 1981.

45. Leis, J.M. Measurement of swimming ability in larval marine fishes: Comparison of critical speed with in situ speed. Mar. Ecol. Prog. Ser. 2020, in press. [CrossRef]

46. Stephen, M.A. Use of the kolmogorov-smirnov, cramer-von mises and related statistics without extensive tables. J. R. Stat. Soc. Ser. B. 1970, 32, 115-122. [CrossRef]

47. R Core Team. R: A Language and Environment for Statistical Computing; R Foundation for Statistical Computing: Vienna, Austria, 2019; p. 201. Available online: http://www.r-project.org/ (accessed on 1 October 2020).

48. Agostinelli, C.; Lund, U. R Package Circular: Circular Statistics (version 0.4-93, 2017). Available online: https://r-forge.r-project.org/projects/circular/ (accessed on 1 October 2020). 
49. Wickham, H. Tidyverse: Easily Install and Load the 'Tidyverse', R package version 1.2. 1; R Core Team: Vienna, Austria, 2017.

50. Forsgren, E.; Dupont, S.; Jutfelt, F.; Amundsen, T. Elevated CO2 affects embryonic development and larval phototaxis in a temperate marine fish. Ecol. Evol. 2013, 3, 3637-3646. [CrossRef]

51. Blaxter, J. Pattern and variety in development. Fish Physiol. 1988, 11, 1-58. [CrossRef]

52. Downie, A.T.; Illing, B.; Faria, A.M.; Rummer, J.L. Swimming performance of marine fish larvae: Review of a universal trait under ecological and environmental pressure. Rev. Fish Biol. Fish. 2020, 30, 93-108. [CrossRef]

53. Fisher, R.; Hogan, J.D. Morphological predictors of swimming speed: A case study of pre-settlement juvenile coral reef fishes. J. Exp. Biol. 2007, 210, 2436. [CrossRef] [PubMed]

54. Berenshtein, I.; Faillettaz, R.; Irisson, J.-O.; Kiflawi, M.; Siebeck, U.E.; Leis, J.M.; Paris, C.B. Fish larvae consistently use external cues for orientation. In Proceedings of the 44th Larval Fish Conference, Mystic, CT, USA, 21-26 June 2020.

55. Foretich, M.A.; Paris, C.B.; Grosell, M.; Stieglitz, J.D.; Benetti, D.D. Dimethyl sulfide is a chemical attractant for reef fish larvae. Sci. Rep. 2017, 7, 2498. [CrossRef]

56. Horváth, G.; Varjú, D. Underwater refraction-polarization patterns of skylight perceived by aquatic animals through Snell's window of the flat water surface. Vis. Res. 1995, 35, 1651-1666. [CrossRef]

57. Rossi, A.; Irisson, J.-O.; Levaray, M.; Pasqualini, V.; Agostini, S. Orientation of Mediterranean fish larvae varies with location. Mar. Biol. 2019, 166, 100. [CrossRef]

58. Fuiman, L.A.; Higgs, D.M. Ontogeny, growth and the recruitment process. In Early Life History and Recruitment in Fish Populations; Springer: Dodlerk, The Netherlands, 1997; pp. 225-249. [CrossRef]

59. Codling, E.A.; Hill, N.A. Sampling rate effects on measurements of correlated and biased random walks. J. Theor. Biol. 2005, 233, 573-588. [CrossRef]

60. Viswanathan, G.M.; Buldyrev, S.V.; Havlin, S.; Da Luz, M.G.E.; Raposo, E.P.; Stanley, H.E. Optimizing the success of random searches. Nature 1999, 401, 911-914. [CrossRef]

61. Benetti, D.D.; Iversen, E.S.; Ostrowski, A.C. Growth rates of captive dolphin, Coryphaena hippurus, in Hawaii. Fish. Bull. 1995, 93, 152-157.

62. Graeb, B.D.S.; Dettmers, J.M.; Wahl, D.H.; Cáceres, C.E. Fish size and prey availability affect growth, survival, prey selection, and foraging behavior of larval yellow perch. Trans. Am. Fish. Soc. 2004, 133, 504-514. [CrossRef]

63. Spudich, J.L.; Yang, C.-S.; Jung, K.-H.; Spudich, E.N. Retinylidene proteins: structures and functions from archaea to humans. Annu. Rev. Cell Dev. Biol. 2000, 16, 365-392. [CrossRef] [PubMed] 